\title{
OPEN Microplastics in fish and fishmeal: an emerging environmental challenge?
}

\author{
Christina J. Thiele ${ }^{1 凶}$, Malcolm D. Hudson ${ }^{1}$, Andrea E. Russell ${ }^{2}$, Marilin Saluveer ${ }^{1,3}$ \& \\ Giovanna Sidaoui-Haddad ${ }^{1}$
}

Microplastics are contaminants of emerging concern; they are ingested by marine biota. About a quarter of global marine fish landings is used to produce fishmeal for animal and aquaculture feed. To provide a knowledge foundation for this matrix we reviewed the existing literature for studies of microplastics in fishmeal-relevant species. $55 \%$ of studies were deemed unsuitable due to focus on large microplastics (>1 mm), lack of, or limited contamination control and polymer testing techniques. Overall, fishmeal-relevant species exhibit 0.72 microplastics/individual, with studies generally only assessing digestive organs. We validated a density separation method for effectiveness of microplastic extraction from this medium and assessed two commercial products for microplastics. Recovery rates of a range of dosed microplastics from whitefish fishmeal samples were $71.3 \pm 1.2 \%$. Commercial samples contained $123.9 \pm 16.5$ microplastics per $\mathrm{kg}$ of fishmeal-mainly polyethyleneincluding $52.0 \pm 14.0$ microfibres-mainly rayon. Concentrations in processed fishmeal seem higher than in captured fish, suggesting potential augmentation during the production process. Based on conservative estimates, over 300 million microplastic particles (mostly $<1 \mathrm{~mm}$ ) could be released annually to the oceans through marine aquaculture alone. Fishmeal is both a source of microplastics to the environment, and directly exposes organisms for human consumption to these particles.

In recent decades, marine debris composition has seen a shift from natural materials such as seaweeds, shells, pumice and wood floating the oceans to a domination by plastic. Studies suggest that $60-80 \%$ of marine debris on shorelines, the seafloor and floating in the oceans consist of plastic ${ }^{1-5}$. All plastic debris can be traced back to human activities, either on land or at sea. Plastic debris $\leq 5000 \mu \mathrm{m}$ is generally termed microplastic ${ }^{6}$, with the larger fraction $(>1000 \mu \mathrm{m})$ being classed as 'large microplastic' (ISO/TR 21960:2020). Multiple sources of microplastics exist. Primary microplastics are plastic particles purposefully produced to be of small size either as a raw material or end-product, such as resin pellets for general production of plastic items, and microbeads as abrasives for industrial use and personal care products ${ }^{7,8}$. Secondary microplastics stem from the disintegration of larger plastic items. Such secondary microplastics can be fragments generated through weathering and disintegration processes from plastics already present in the environment, but they can also be microfibres released from laundry or paint flaking off the bottom of marine structures or vessels ${ }^{7,9-11}$. Microplastics have been found in all marine compartments, including biota ${ }^{8,12}$. Trophic transfer has been shown experimentally ${ }^{13}$. The exposure potential of consumers to microplastics is studied by establishing microplastic concentrations in prey and organisms for human consumption. Fish and other marine organisms harvested and cultured for human consumption have been shown to contain microplastics ${ }^{12,14-17}$, but methodological differences can hinder interstudy comparisons. The use of different extraction techniques is often mentioned as such hindrance for comparison. Contamination controls and aspects of polymer identification are rarely scrutinised ${ }^{18-24}$. Effects on organisms such as fish through ingestion of microplastics and associated chemicals have been studied in controlled laboratory experiments, and include hepatic stress, endocrine disruption, behaviour alterations, but numerous studies did not find any effects through microplastic exposure ${ }^{25-28}$. Common criticism of such studies include exposing study organisms to environmentally unrealistic concentrations of microplastics ${ }^{29}$ and the lack of inclusion of control particles for ingestion ${ }^{30}$. Effects of ingestion in wild biota or humans are currently unknown.

Microplastic exposure potential in marine fish, for example, is likely to arise from ingestion of particles in the water column or on the seafloor resembling prey or by ingesting prey that previously ingested microplastics

\footnotetext{
${ }^{1}$ Faculty of Environmental and Life Sciences, Centre for Environmental Science, University of Southampton, University Road, Southampton SO17 1BJ, UK. 'Faculty of Engineering and Physical Sciences, School of Chemistry, University of Southampton, University Road, Southampton SO17 1BJ, UK. ${ }^{3}$ Present address: Centre for Environmental Policy, Imperial College London, London SW7 1NW, UK. ${ }^{\circledR}$ email: c.j.thiele@soton.ac.uk
} 


\begin{tabular}{|c|c|}
\hline \multicolumn{2}{|l|}{ Main marine fish species for fishmeal production } \\
\hline \multicolumn{2}{|l|}{ Whole specimens } \\
\hline Peruvian, Japanese, European and Southern African anchovy & Engraulis ringens, E. japonicus, E. encrasicolus \& E. capensis \\
\hline Blue whiting and Southern blue whiting & Micromesistius poutassou and M. australis \\
\hline Sandeels & Ammodytes spp. \\
\hline Gulf and Atlantic menhaden & Brevoortia patronus and B. tyrannus \\
\hline European sprat & Sprattus sprattus \\
\hline Kawakawa & Euthynnus affinis \\
\hline Capelin & Mallotus villosus \\
\hline Pacific anchoveta & Cetengraulis mysticetus \\
\hline Atlantic and Mediterranean horse mackerel & Trachurus trachurus and T. mediterraneus \\
\hline Pacific sardine, Californian and Southern African pilchard & Sardinops sagax \\
\hline Norway pout & Trisopterus esmarkii \\
\hline \multicolumn{2}{|l|}{ Wastes and by-products ${ }^{\mathrm{a}}$} \\
\hline Herrings $^{b}$ & Clupea harengus, C. pallasii and Strangomera bentincki \\
\hline Skipjack tuna & Katsuwonus pelamis \\
\hline Yellowfin tuna $^{\mathrm{b}}$ & Thunnus albacares \\
\hline Jack and horse mackerel $^{\mathrm{b}}$ & Trachurus spp. \\
\hline Salmonids & Oncorhynchus spp. and other Salmonidae \\
\hline Alaska pollock & Gadus chalcogrammus \\
\hline Atlantic cod & Gadus morhua \\
\hline Hakes & Merluccius spp. \\
\hline Saithe & Pollachius virens and P. pollachius \\
\hline European pilchard ${ }^{\mathrm{b}}$ & Sardina pichardus \\
\hline Atlantic and chub mackerel $^{\mathrm{b}}$ & Scomber scombrus and S. japonicus \\
\hline Haddock & Melanogrammus aeglefinus \\
\hline Patagonian grenadier & Macruronus magellanicus \\
\hline Pacific thread herring & Opisthonema spp. \\
\hline Mote sculpin & Normanichthys crockeri \\
\hline Sardinellas ${ }^{\mathrm{b}}$ & Sardinella spp. \\
\hline
\end{tabular}

Table 1. Main marine fish species used in fishmeal production, divided into two categories: 'whole specimens' and 'wastes and by-products'. Both categories in descending order of overall global catch rates ${ }^{37,38}$. Adapted from $^{32,33,36-38}$. ${ }^{a}$ By-products (e.g. offal) and other wastes from food processing industry, fisheries discards

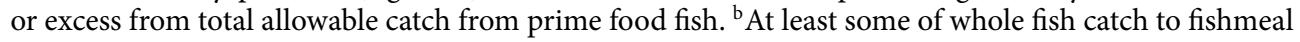
reduction.

themselves ${ }^{12}$. Aquacultured organisms, including marine fish, are often provided with feed. Fishmeal is often the base for such feeds. Fishmeal is produced from target or bycatch fishing as well as fish by-products ${ }^{31,32}$. About $25 \%$ of global commercial marine fisheries landings are destined for the production of fishmeal and fish oil ${ }^{33}$. Fishmeal derivates form part of the human food chain; direct consumption is via pressed fish oil and indirect consumption through feed for poultry, pigs and aquaculture ${ }^{34,35}$. Fishmeal and fish oil are mainly produced with small pelagic species, but also trimmings and wastes from food processing, by-catches and excess of allowable catch quotas $^{32,33,36-38}$ (Table 1). Evidence that such species contain microplastics exists ${ }^{14-16}$.

Evidence about microplastics in fishmeal is only just starting to emerge. The research aims of this present study are threefold: (1) to review the existing literature of microplastics in fishmeal-relevant fish species to establish the potential contribution of the raw material to fishmeal, including critically examining the methods used; (2) to establish a suitable method to extract small microplastics from fishmeal. To our knowledge, two studies have investigated this matrix to date: both studies focus on microplastics $\geq 149 \mu \mathrm{m}^{39,40}$. By extending the size range, a more accurate picture of microplastic contamination in fishmeal should be obtained. (3) To test such method on commercially available samples to establish if microplastics in fishmeal should be a concern. The results will improve our understanding of the potential for microplastics to enter the (human) food chain via fishmeal and inform future assessments of associated risk to health and food security.

\section{Results}

Review of relevant studies: microplastics in fish that are used in fishmeal production. General methods. Twenty-nine studies investigating microplastics in fishmeal-relevant fish were included in this review; 34 were excluded after applying criteria outlined in the methods section. Detailed information on individual studies can be found in Supplementary Table S1. Studies were published between 2013 and 2020. None of the studies assessed whole body specimens. Twenty-six assessed the gastrointestinal tract or parts thereof, 
one investigated the gastrointestinal tract and gills and two the gastrointestinal tract, gills and other organs (one of the latter also included $5 \mathrm{~g}$ subsamples of muscle). Most studies used extraction techniques to isolate microplastics except for nine studies. $\mathrm{KOH}$ was most commonly used (12 studies, three of which further performed density separation). $\mathrm{HNO}_{3}$ or $\mathrm{NaClO} / \mathrm{HNO}_{3}$ was used by two studies, while Proteinase- $\mathrm{K}$ and $\mathrm{H}_{2} \mathrm{O}_{2}$ and a $\mathrm{NaCl}$ density separation without additional digestion were used once each. In most cases, reagents are not filtered prior to use (see Supplementary Table S1 for detailed information).

Polymer identification techniques and assessment rates. The most used polymer identification technique was Fourier-transform infrared (FTIR) spectroscopy (25 studies), three used Raman spectroscopy and one study combined both. Of the excluded studies, 18 studies did not apply any chemical identification technique, seven did not state either how many of the potential microplastics were assessed or they assessed less than $10 \%$ by FTIR. A range of spectral libraries were used for positive identification of plastics. Of the included 29 studies, 16 did not report a minimum match score for positive identification against library searches. One study used a minimum score of $60 \%$ and nine used $70 \%$, of which three visually assessed the spectral comparison results when the score was $\geq 60 \%$. The remaining studies set the score to $80 \%$ (one study) and $85 \%$ (two studies). Twenty-six studies reported detailed information of how many potential microplastics isolated from fish were assessed with spectroscopy. These studies assessed on average $62.6 \%( \pm 37.3 \%)$ of potential microplastics-ranging $10-100 \%$. The lowest quantity assessed was two, which was $100 \%$ of particles found; the highest was 2649 particles, equalling $77 \%$ of potential microplastics found. Interestingly, $66.6 \%$ of the lowest spectroscopy assessment rates (i.e. $<50 \%$ of particles assessed) coincided with a low number of absolute particles assessed (assessment rates of 10-36\% equalling assessment of 3-38 potential microplastics). Eleven studies provided an insight into how many particles proved to be plastic (one of these studies reported values individually per both species analysed). Outcomes were variable: mean $66.6 \%$ ( $\pm 24.4 \%)$, ranging $31-94 \%$ of potential microplastics positively being identified as plastics.

Target size. Seventeen studies assessed microplastics $<100 \mu \mathrm{m}$, two had a limit of detection (LOD) or filter size between 100 and $200 \mu \mathrm{m}$ and one assessed particles $\geq 500 \mu \mathrm{m}$. Nine studies did not state the filter size or LOD size of their method. Of the studies that did not report LOD/filter size, four also did not report the sizes of the microplastics they presented in their results. Of the studies with LOD/filter size $<100 \mu \mathrm{m}$, seven studies reported finding particles $<50 \mu \mathrm{m}$.

Microplastic categories. Four studies did not report microplastics categories. Concentrating on the fibre category (due to its relevance to airborne contamination ${ }^{16,41-44}$ ), only three studies reported no microfibres, three reported occurrences of $6-20 \%$, three $33-42 \%$, ten studies $55-70 \%$ and the remaining thirteen $\geq 80$, with two reporting $100 \%$ (since some studies reported fibre proportions per individual species, the overall sum here is 36 ).

Contamination control. The use of airborne controls in the absence of cleanrooms or laminar flow cabinets was reported by eight studies, of which two did not report any fibres. The remaining studies reported that 33, $56,62,80$ and $96 \%$ of all microplastics found were fibres. Six studies used a laminar flow cabinet and provided enough information on categories; of those, two did not find/report any fibres and the remaining ones had fibre percentages of 16, 42, 60 and $80 \%$ each. Only one study was performed in a clean room, and incidentally only found fibres. Using the most stringent contamination control by performing airborne controls while also using a laminar flow cabinet, the only study doing this reported $16 \%$ fibres.

Microplastic concentrations in fishmeal-relevant marine fish. Detailed information per species can be found in Supplementary Tables S2 and S3. Fifty-six species were assessed, some-such as Engraulis encrasicolus, E. japonicus, and Trachurus trachurus-were studied more than once. Of the 'whole specimens' category for fishmeal production (Table 1), E. encrasicolus and T. trachurus were the most studied (four times each). Of the 'wastes and by-product' category, Sardina pilchardus was the most studied (5), followed by Decapterus spp., Gadus morhua, Mugil cephalus, Scomber spp. (studied each 4 times). Overall, 1010 specimens of 'whole specimens' for fishmeal species were analysed for microplastics, but for the 20 Trisopterus esmarkii abundance was not reported. Mean abundance of microplastics in fish destined whole for fishmeal production was $0.69 \pm 0.81$ items/specimen, ranging 0-2 items when broken down per species (Fig. 1). In the 'wastes and by-product' category, 1713 specimens were analysed, but microplastic abundance was not reported for 92 specimens. For the remaining, mean microplastic abundance was $0.73 \pm 1.61$ items/specimen. Pooling all studies, mean microplastic concentrations based on 2611 specimens was 0.72 items/individual. Highest mean microplastic abundances per study were reported for E. japonicus with 2.3 items/individual ('whole specimen' category) and Muraenesox cirereus with 7 items/individual ('wastes and by-products' category). As elaborated in results in "General methods" of the "Review of relevant studies: microplastics in fish that are used in fishmeal production" section, concentrations per individual usually refer to concentrations in digestive organs. While individual studies reported absence of microplastics in their studied species, when more than one study was performed per species, usually there was only one study reporting zero concentrations with the exception of Clupea harengus (2 out of 3 studies did not find microplastics) and Gadus morhua (3 out of 4 reported nil microplastics). Based on the review of species destined whole to fishmeal production, approximately 36 microplastics per kilogram of fishmeal can be expected from the raw material. 


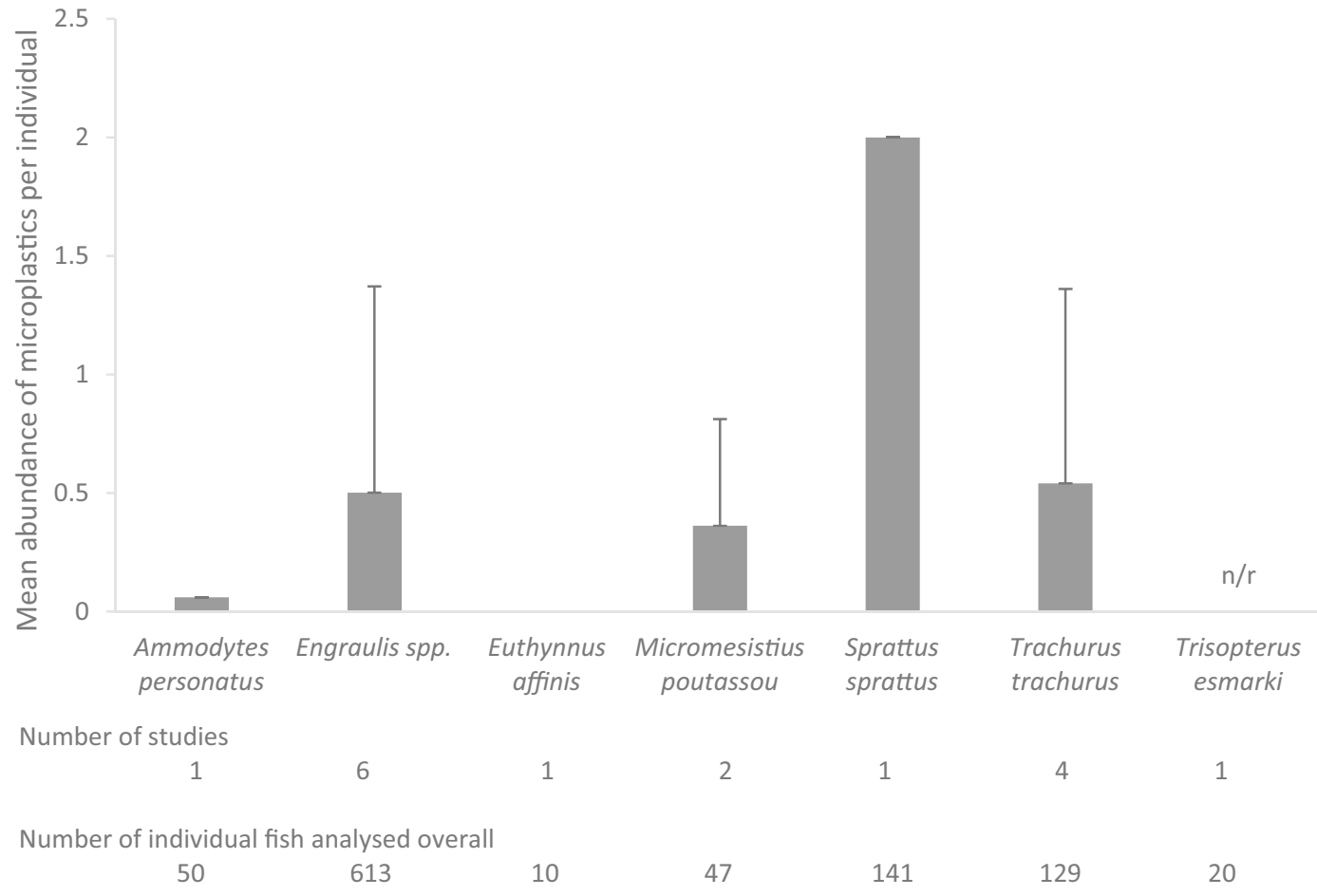

Figure 1. Mean abundance of microplastics per individual in studies assessing microplastics in fishmealrelevant fish species. Only concentrations of 'whole fish' species used in fishmeal production are shown; 12 reviewed studies examined those species-four of those analysed two of such species each. $n / r$ mean abundance was not reported. Error bars are $1 \times$ standard deviation of mean abundance per species of each study.

Method development and assessment for extraction of microplastics from fishmeal: $\mathrm{NaCl}$ density separation and recovery rates. Technique 1. Filtration of fishmeal digestates (exposed to 10\% $\mathrm{KOH}$ ) was not achieved using $25-\mu \mathrm{m}$ filters. Supernatants of density separation (using $\mathrm{NaCl}$ ) were successfully filtered over $25 \mu \mathrm{m}$. Overall microplastics recovery rate of dosed samples was $60.3 \pm 12.1 \%$, but with a variation of an order of magnitude lower within each fishmeal type. The overall recovery rate from dosing trials with whitefish fishmeal was $71.3 \pm 1.2 \%$, ranging $46.7 \%$ for polypropylene fragments to $100.0 \%$ for polystyrene fragments (see Supplementary Table S5 for recovery rates per polymer type). Microplastic recovery from sardine/ anchovy fishmeal was $49.3 \pm 1.2 \%$, ranging $30.0 \%$ for PET and rayon fibres to $76.7 \%$ for polystyrene fragments. By polymer density, $49.2 \pm 25.0 \%$ of particles of a density $>1.2 \mathrm{~g} / \mathrm{ml}$ were recovered. Overall, $48.7 \%$ of dosed particles were recovered during overflow \#1, 7.3\% with overflow \#2 and $4.3 \%$ with overflow \#3.

Technique 2. Recovery rates of microplastics using the Sediment-Microplastic Isolation unit were 31.9 $\pm 8.3 \%$, with recovery rates from whitefish being $38.3 \pm 2.0 \%$ and from sardine/anchovy fishmeal $25.6 \pm 6.9 \%$.

Microplastics in commercial fishmeal samples. Procedural blanks were free from potential microplastics. Airborne controls (dampened filter papers, $n=4$ ) contained in total seven fibres, which had accumulated during the processing of 24 fishmeal/procedural blank filters. Since numbers are low, fibres are not discounted from samples, but all 14 fibres found in the fishmeal samples are presented separately. 57 potential microplastics were visually identified (including 14 fibres), plus one fragment $>5000 \mu \mathrm{m}(6436 \mu \mathrm{m})$. Fragments and microsheet extracted with this method ranged 56-3701 $\mu \mathrm{m}$, fibre diameters were 12-57 $\mu \mathrm{m}$ and fibre length approximately 76 to $3200 \mu \mathrm{m}$. Size distribution was estimated (Fig. 2). Mean fragment size, excluding the 6436$\mu \mathrm{m}$ particle, was $778 \pm 944 \mu \mathrm{m}$ (median $408 \mu \mathrm{m}$ ), mean fibre diameter was $24 \pm 15.3 \mu \mathrm{m}$ (median $16 \mu \mathrm{m})$ and mean length $1299 \pm 935 \mu \mathrm{m}$ (median $1200 \mu \mathrm{m}$ ).

Approximately $90 \%$ of potential microplastics (52; including approximately $23 \%$ of fibres) were assessed with Raman spectroscopy. Of these, no spectrum could be achieved for 15 particles (none of which were fibres). Eleven particles were confirmed to be biomaterials, such as tricalcium phosphate. Three fibres were of natural origin. Nineteen potential microplastics were confirmed to be plastic (plus eight fibres). The 6436- $\mu \mathrm{m}$ particle was also plastic. Based on this and corrected for recovery rates of $71.3 \%$ and spectroscopy assessment rate of $89.1 \%$, the mean concentration of non-fibrous microplastics per kg of fishmeal is $71.9 \pm 2.5$ items. Mean microfibre concentrations were $52.0 \pm 14.0$ fibres $/ \mathrm{kg}$ fishmeal. Concentrations of 'inconclusive' non-fibrous particles (mainly identified as dyes) were $6.4 \pm 9.1$ items and for fibres $18.1 \pm 25.6$ items.

Microplastic categories in fishmeal were $21.1 \%$ fragments, $36.8 \%$ microsheet/film and $42.1 \%$ microfibres. Of non-fibrous microplastics, $54.5 \%$ were made of polyethylene (Fig. 3a,b), $18.2 \%$ acrylonitrile butadiene styrene (Fig. 3c,d) and 9.1\% each nylon, PET/polyester and the other likely to be acrylonitrile/butadiene/styrene resin 


\section{Kernel Density Plot \\ Used hOpt $=165.919090294831$}

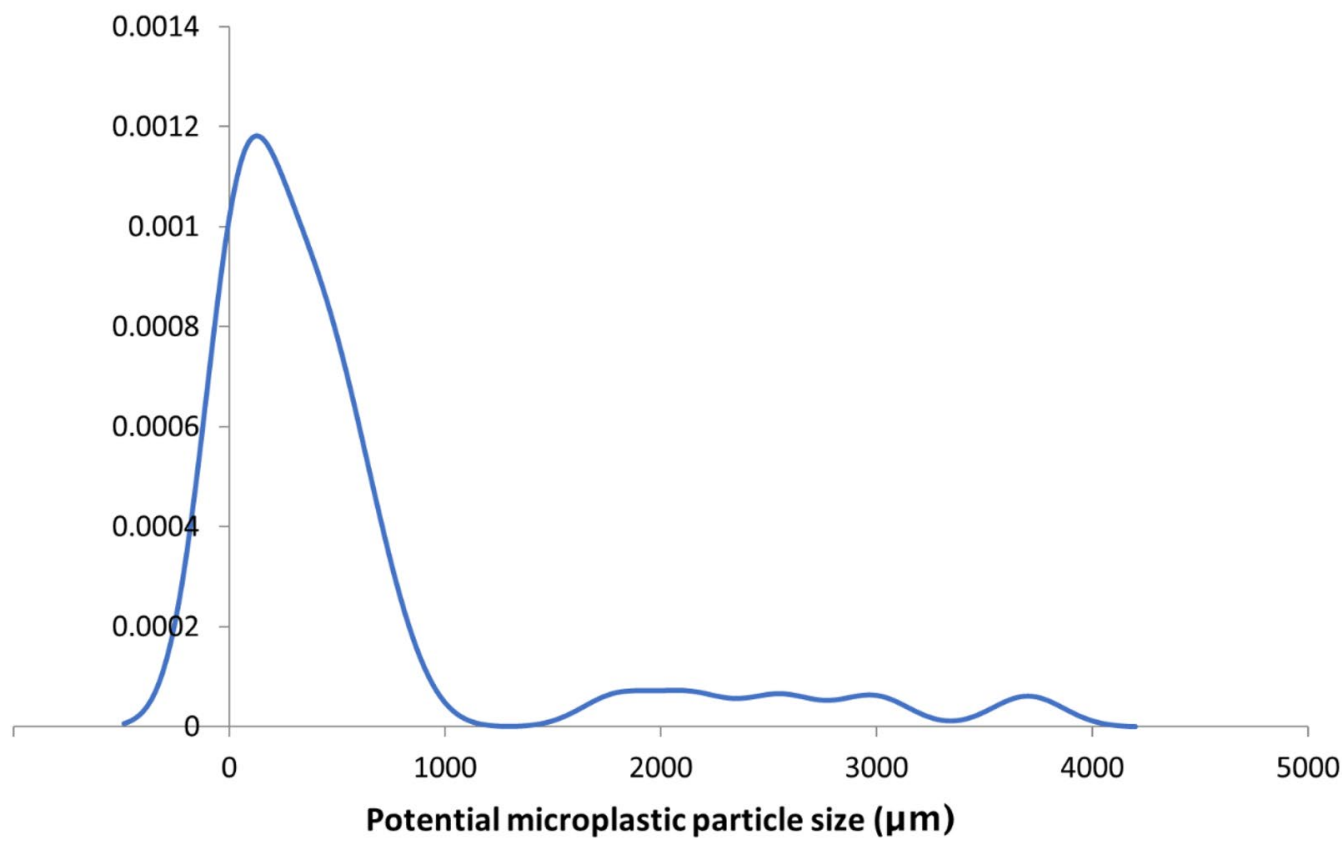

Figure 2. Kernel density estimation of potential microplastic size distribution based on 40 out of 58 particles extracted with $\mathrm{NaCl}$ density separation from whitefish fishmeal $(\mathrm{n}=6) .87 .2 \%$ were microparticles $\leq 1000 \mu \mathrm{m}$ and $12.8 \%$ microparticles $1000-5000 \mu \mathrm{m}$. Note: the single $>5000 \mu \mathrm{m}$ particle $(6436 \mu \mathrm{m})$ is excluded from microplastic calculations.

or styrene/acrylonitrile copolymer (Fig. 3e). Of microfibres, $62.5 \%$ were rayon, $12.5 \%$ each nylon, PET/polyester and polypropylene. Non-fibrous microplastics in fishmeal were predominantly blue, followed by white and red. Microfibres were blue and black. Potential microplastics that were not confirmed to be so, included a white fragment (Fig. 3f) but also numerous orange spheroids (see next to microsheet in Fig. 3c). No spectra could be obtained of the latter. The only plastic particle larger than a microplastic was a blue LDPE film. Mean match score was $87 \%$. The lowest score of $61 \%$ was obtained through peak matching, all remaining scores were $>70 \%$ and obtained through component analysis.

\section{Discussion}

Here we present a suitable extraction technique for microplastics from fishmeal. Our review has shown that potassium hydroxide digestions are regularly used for microplastic extractions from gastrointestinal fish tissues. $\mathrm{KOH}$ has also been used for fishmeal digestions ${ }^{39,40}$, but recovering microplastics $<150 \mu \mathrm{m}$ does not seem possible for fishmeal with this method. The investigation of small microplastics is important, but previously often neglected. For one, smaller particles may be more prevalent. For example, $80 \%$ of microplastics in E. japonicus were $150-1000 \mu \mathrm{m}$ and all microplastics found in S. pilchardus were $39-857 \mu \mathrm{m}^{15,17}$. Across numerous species, Bour et al. ${ }^{42}$ found $12 \%$ of microplastics $41-100 \mu \mathrm{m}$ and $47 \% 100-200 \mu \mathrm{m}$. Secondly, smaller particles may be more likely to translocate to other tissues ${ }^{45}$-this has been shown in bivalve models ${ }^{46}$ but also observed in wild fish liver ${ }^{47}$. We successfully trialled $\mathrm{NaCl}$ flotation to extract microplastics from fishmeal. A simple overflowing technique provided the highest recovery rates of spiked microplastics; $35 \%$ of potential microplastics in our samples were $<150 \mu \mathrm{m}$ highlighting the importance of recovering smaller microplastics and the suitability of our method. Flotation recovery rates were lower than they are for digestions ${ }^{21,23}$, but still averaged $60 \%$ and up to $100 \%$ for certain polymers depending on the type of fishmeal. Even polymers of greater density than the $\mathrm{NaCl}$ solution (e.g. PET/polyester, rayon) were extracted with our technique. In addition, low standard deviations within the same type of fishmeal suggest high repeatability of recovery rates.

We identified numerous limitations in studies investigating microplastics in fish. Over half of the initially qualifying studies were excluded for three reasons: focus on large microplastics (i.e. $>1 \mathrm{~mm}$ ), lack of polymer identification techniques or limited identification assessment rates. Knowledge about 'true' microplastics $(\leq 1 \mathrm{~mm}$ in line with ISO/TR 21960:2020) is imperative considering their prevalence and potential hazardousness as elaborated above. Lack, or limited use of stringent confirmatory techniques is a reoccurring issue in microplastics research. Our review has highlighted that spectroscopy assessment rates in many previous studies might be an issue. Numerous studies were excluded from the review for not testing polymer composition at all, despite reporting 'microplastics.' Often, when small numbers of potential microplastics were found, only a small fraction of these (typically $\leq 38$ particles) were tested. Polymer identification is important, especially to reduce overestimates 

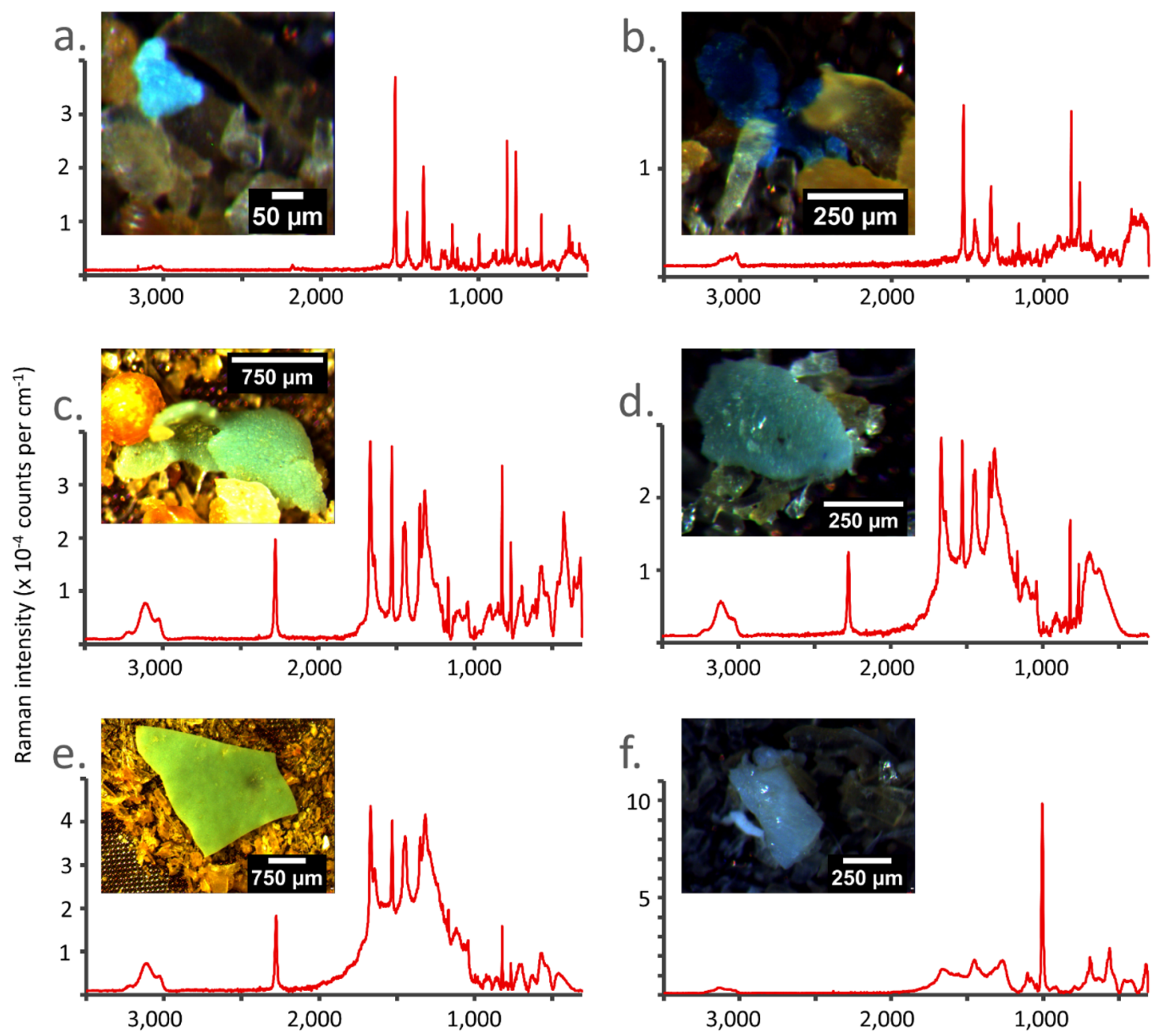

Raman shift $\left(\mathrm{cm}^{-1}\right)$

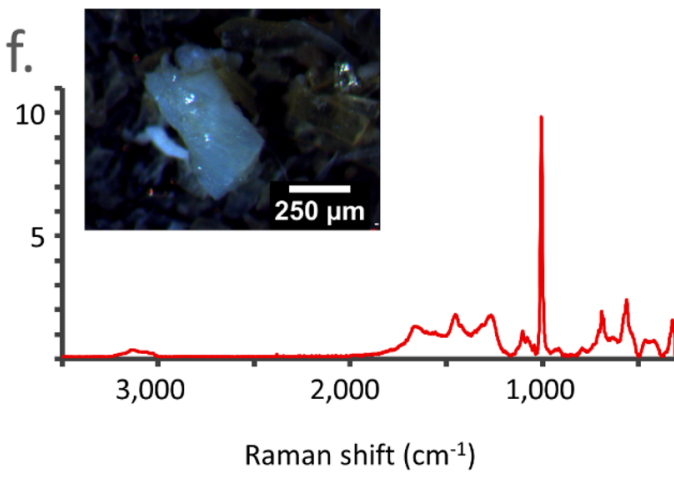

Figure 3. Identification of six particles found in fishmeal samples. (a,b) Microfilms identified as acrylonitrile butadiene styrene-match score of 88.0 and $93.3 \%$ respectively, (c,d) polyethylene microfilms-match score of 86.3 and $86.1 \%$ respectively, (e) acrylonitrile/butadiene/styrene resin or styrene/acrylonitrile copolymer fragment with blue dye-match score $90.2 \%$, (f) fragment of biomaterial (top suggestion: calcium phosphatematch score $93.6 \%$ ).

of potential microplastic counts. Based on the review and our own study, as little as $1 / 3$ of potential particles may prove to be plastic, averaging a confirmation rate of $67 \%$. For this reason, it is imperative to conduct spectroscopy or other polymer identification methods. In the absence of automated or semi-automated systems, a subset of at least 50 particles and all particles $20-100 \mu \mathrm{m}$ should be analysed to confirm their polymeric identity-as previously recommended by Galgani et al. ${ }^{19}$.

A further issue relates to confirming spectral library search results. Match scores, a computation of the quality of similarity between the spectrum of a potential microplastic against spectra from chosen libraries based on a Hit Quality Index and scaled up to $100^{48,49}$, are generally used to confirm polymeric identity. Of the studies that provided such information, all set the minimum match score to $60 \%$ or higher. Generally in spectroscopy, $>80 \%$ would be considered a high quality match and $50-80 \%$ a medium quality match ${ }^{48}$. Medium quality matches can be expected from environmental microplastics often exhibiting poor/degraded spectral quality (personal observation). No matter the score, $\mathrm{Smith}^{48}$ suggests to visually compare all results. This was only done by three studies, and only for the match range $60-70 \%$. To improve interstudy comparability we recommend reporting of particle assessment rates, which spectral libraries were used, and the minimum score applied to obtain a positive identification. Such information is as vital as reporting contamination mitigation techniques and will aid comparison between studies.

Our results show that microplastic is present in our samples, and that concentrations in fishmeal are low and solely seem to consist of secondary microplastics. Based on the review of fishmeal-relevant fish species, mean microplastic concentrations are 0.7 per individual and could, therefore, be as little as 36 microplastics $/ \mathrm{kg}$ (mean minimum size assessed $146 \mu \mathrm{m}$ ) in fishmeal made with fish destined whole to fishmeal production. When waste products such as gastrointestinal tracts are included and minimum particle sizes assessed are $<146 \mu \mathrm{m}$, 


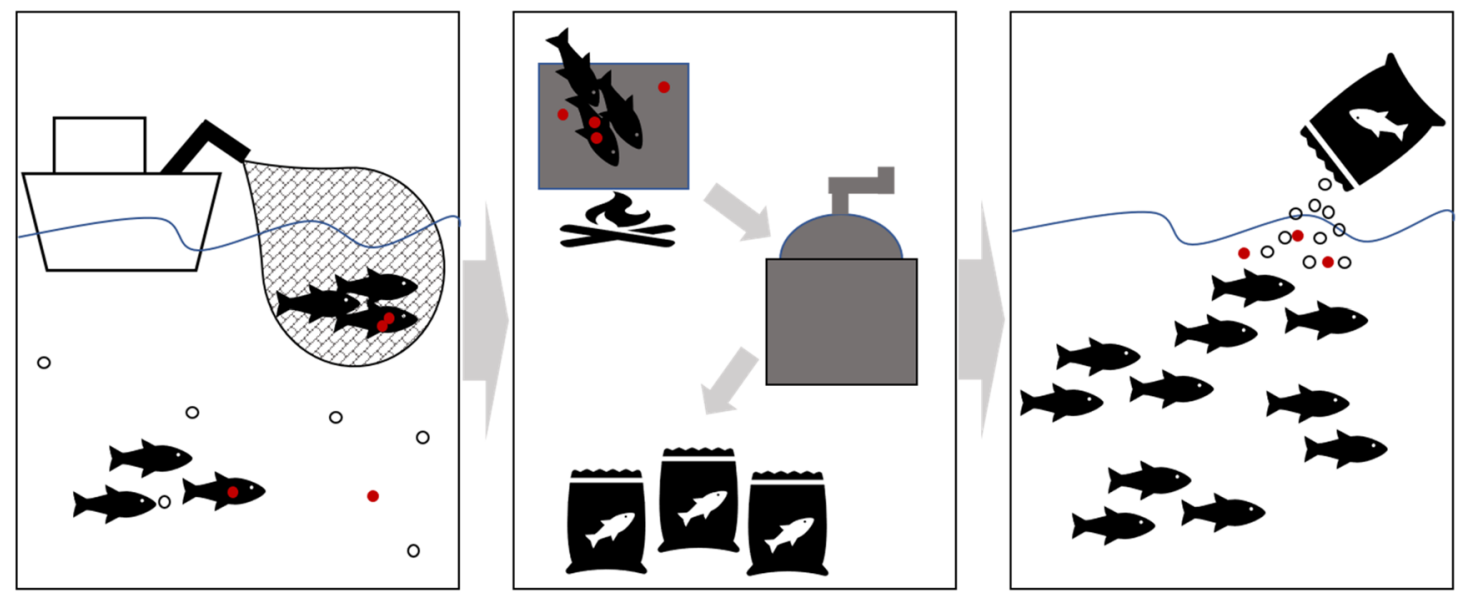

Figure 4. Fishmeal as a pathway for microplastics to the marine environment from capture fisheries via fishmeal production to mariculture feed. Food particles (open circle), microplastics (red filled circle). Microplastic fragmentation possible during fishmeal production steps (heating and grinding) or through contamination, leading to increased microplastic concentrations fed back into the environment.

microplastic concentrations may well be higher. It seems that concentrations in commercial fishmeal (even when not including any microfibres) are higher than in the raw material. This observation can be extended to other recent fishmeal studies. Karbalaei et $\mathrm{al}^{40}$ investigated three types of fishmeal. The fishmeal produced with whole specimens of Indian mackerel (Rastrelliger kanagurta) contained 200-300 microplastics per $\mathrm{kg}^{40}$. Hanachi et al. ${ }^{39}$ analysed salmon, sardine and kilka fishmeal from Iran. They reported approximately 4000-6000 microplastics per $\mathrm{kg}^{39}$. Microplastic concentrations of these species are listed in Supplementary Table S3, and as with our samples, the raw material seems to contain lower concentrations of microplastics. This overall pattern of increased microplastic concentrations from wild caught fish to fishmeal products warrants further investigation: production processes could lead to fragmentation of existing microplastics in the raw material, and/or product manufacturing, handling and storage may be introducing microplastic contamination to the end-product. Microfibres could potentially enter the production process at any point. This is supported by widespread microfibre contamination in the atmosphere ${ }^{41,43,44,50}$. Fragments or films may enter with the raw material, or in case of the latter, also during storage of the final product. Most of the microplastics we found were polyethylene-a material used to make storage bags for fishmeal ${ }^{31,39}$.

Fishmeal samples analysed here contained about half the microplastic concentrations found by Karbalaei et al. ${ }^{40}$ and even less than the quantities reported by Hanachi et al. ${ }^{39}$. Methodological differences are unlikely to result in such a discrepancy. Those studies digested samples with $\mathrm{KOH}^{39,40}$. Recovery rates from biological tissues using $\mathrm{KOH}$ have been reported as $>93 \%$ from whole fish and $86.2 \%( \pm 7.9 \%)$ from bivalve tissues ${ }^{21,23}$, therefore higher than recovery rates achieved here. However, while we applied the recovery rates as a correction factor to our results, others did not. Further, using a pore size of $149 \mu \mathrm{m}^{39,40}$, smaller particles are likely to have been lost. We recovered three fragments and eleven fibres $<150 \mu \mathrm{m}$. It might therefore be that either the fish in the other studies or parts thereof contained higher microplastic concentrations at the time of harvest, that microplastic contamination was introduced during the production processes or more aggressive physical forces were used in pressing and grinding leading to fragmentation of microplastics that were present. It is therefore paramount to conduct additional research into microplastics in fishmeal to help understand those discrepancies between studies, in addition to differences between raw materials and end products.

Fishmeal is a pathway for microplastics into the environment (partly returning microplastics that were previously taken out, but also potentially adding new ones) since a proportion of fishmeal is thrown into the sea as aquaculture feed (Fig. 4). Based on the application of 2.5 million tonnes of fishmeal per year for marine aquaculture ${ }^{33}$, currently about 180-310 million pieces of microplastics might be put into the oceans per year and may equate to adding 10-1670 kg of microplastics annually (see Supplementary Section "Quantification of theoretical microplastic concentrations in fishmeal online for calculations"). These global extrapolations may be a relatively small, compared to 65 million microplastics being released daily from individual wastewater treatment plants ${ }^{11}$ for example. However, based on our results almost $90 \%$ of those microplastics could be $<1 \mathrm{~mm}$ in size. Furthermore, fishmeal is also used in freshwater aquaculture and fish farms, including lakes ${ }^{32}$. Also, the application is intensive at aquaculture sites as many of which are in low energy coastal waters or lochs where dispersal may be limited.

In addition to simply increasing microplastic concentrations in the environment, the microplastic exposure potential is increased. Fishmeal is an integral part of the food chain by being fed to poultry, pigs and aquaculture amongst others ${ }^{31}$. Hence, these organisms are directly exposed to the microplastics mixed with their feed. A laboratory study has already confirmed ingestion of microplastics present in fishmeal in Cyprinus carpio ${ }^{39}$. However, microplastic residence time in fish is likely to be short. Bråte et al. ${ }^{51}$ found that fish with empty stomachs did not have large microplastics in their system. Ingested plastic particles may often pass through without harming the organism visibly ${ }^{52}$. Also, since particle size of encountered microplastics is in the range of prey items and fishmeal particles, such particles may be processed by the digestive systems in a comparable fashion. 
Similarly, chickens (Gallus gallus domesticus) are known to ingest microplastics ${ }^{53}$. Huerta Lwanga et al. ${ }^{53}$ found microplastics ranging 100-1000 $\mu \mathrm{m}$ in chicken faeces, and larger particles in gizzards and chicken crops. Only finding smaller particles in faeces, but larger in crop and gizzards, suggests that particles $>1000 \mu \mathrm{m}$ may not easily pass through the digestive system of chickens. We only found low numbers of potential microplastics above this size. The largest microplastic found by others in fishmeal was $810 \mu \mathrm{m}^{39}$. Based on the evidence to date, microplastics from fishmeal are therefore likely to pass through chickens' intestines. Chicken manure is widely used as a soil improver ${ }^{54}$, posing the question where those microplastics might go next. There is currently no evidence to suggest that microplastics in fishmeal could threaten food security in any way. The presence of microplastics in fishmeal does have limited implications for the human food chain; namely the theoretical potential of small microplastics and nanoplastics translocating into edible parts of organisms consumed by humans and fed with fishmeal or exposure to chemicals innate or adhering to microplastics. The latter implication is currently mainly based on extrapolated knowledge from macroplastics to microplastics ${ }^{55}$. For both cases, more research is needed to establish if microplastics or chemical exposure related to those particles could harm animals feeding on fishmeal, especially because we have limited knowledge about particles $>55 \mu \mathrm{m}$ in fishmeal.

Some potential limitations should be highlighted. Estimated microplastic concentrations that can theoretically be expected in fishmeal based on our review of fishmeal-relevant fish species might be an underestimate. This is because fish weight was often not provided and because most studies investigate microplastics in the digestive system rather than whole organisms. The gastrointestinal tract, which is removed prior to human consumption-except for small pelagic fish eaten whole or without the head, is increasingly processed together with trimmings and other waste products such as organs for fishmeal ${ }^{31,34,35}$. Evidence of microplastic presence in tissues outside the digestive system is slowly emerging. Microplastics have been found in the gills of a number of fish species ${ }^{56,57}$. They have further been found in the livers of European anchovies (Engraulis encrasicolus), but not in the livers or muscle of a number of other important commercial species ${ }^{47,56-59}$. Sample quantities may not have be adequate, however; Su et al. ${ }^{58}$ assessed subsamples of livers and muscle of approximately $0.7 \mathrm{~g}$ and $3.1 \mathrm{~g}$ respectively and Huang et al. ${ }^{57}$ assessed tissue subsamples of $5 \mathrm{~g}$. Microplastics in fish muscle have been reported $^{60}$. However, said study did not perform any polymer identification techniques. The global estimate of microplastic concentrations entering the oceans through fishmeal is likely to be an underestimate as well. These calculations were based on our findings in whitefish fishmeal, which even after correcting for recovery rates, were lower than concentrations reported in other studies.

We acknowledge that the use of visual particle assessment and manual Raman spectroscopy are not ideal, as this potentially leads to a proportion of particles being overlooked ${ }^{61}$. However, one aim of our study was to establish if microplastics are present in fishmeal. The visual assessment/manual Raman spectroscopy approach was adequate for this, and we exceeded practices in many recently published studies by testing the large majority (89\%) of the microparticles we could isolate. Furthermore, the visual assessment/manual spectroscopy combination was also applied in all studies we reviewed. About $62 \%$ of the suspected microplastics from the visual assessment were not plastic. This is in line with previously reported numbers ${ }^{18}$.

Our work has highlighted that despite stringent controls, atmospheric contamination may not be avoidable. Numerous studies reviewed here conducted their work in laminar flow cabinets, but only one of those also implemented airborne controls-leading to one of the lowest microfibre proportions of $16 \%{ }^{62}$. For this reason, using airborne contamination monitoring such as dampened filter papers should be considered even in clean environments. Lastly, while we were successful at extracting microplastics from whitefish fishmeal samples with our extraction technique, this method might not be suitable for all types of fishmeal, and further method development is recommended. Despite these limitations our research aims were fulfilled.

\section{Conclusion}

Microplastic extraction from whitefish fishmeal using a simple $\mathrm{NaCl}$ density separation is suitable for fragments/ sheets $>55 \mu \mathrm{m}$ and microfibres with a diameter smaller than this. Fishmeal is a small, yet important source of microplastics to the environment-especially to low energy environments already affected by aquaculture practices. Further research is needed to enable extraction of particles to $1 \mu \mathrm{m}$ and to improve applicability to further fishmeal types. More work is needed to understand the relationship of microplastics in capture fish and fishmeal, and the implications of their presence for direct and indirect consumers of fishmeal given the importance of fishmeal for food security. Reviewing research articles of fishmeal-relevant fish species has highlighted issues, such as a lack of transparency regarding aspects of microplastic identification, that are often ignored but obstruct interstudy comparability. To improve comparability it is imperative to provide size-related information of extracted particles; we also recommend that studies report the proportions of potential microplastics that were assessed using polymer identification techniques (in the absence of automated systems) and the minimum scores for positive identification against spectral library searches that were applied. Lastly, based on our and the reviewed work we suggest the use of airborne contamination monitoring, even in clean environments.

\section{Methods}

Review of relevant studies: microplastics in fish that are used in fishmeal production. A Web of Science search (terms "marine AND micro\$plastic* AND fish") was conducted on 18/03/2020 yielding 560 results. Only research articles investigating microplastic concentrations in adult fish that are of interest for fishmeal (see Supplementary Table S6) were preselected. Of the 65 remaining studies, inclusion in the review was subject to (1) use of polymer identification technique, such as Raman spectroscopy, and assessment of at least $10 \%$ of potential microplastics, (2) focus on 'true' microplastics, i.e. target size range including particles $<1000 \mu \mathrm{m}$ and (3) reporting of at least some contamination control. The rationale for the size exclusion was that numerous studies concentrate on larger microplastics despite extensive evidence of large proportions of 


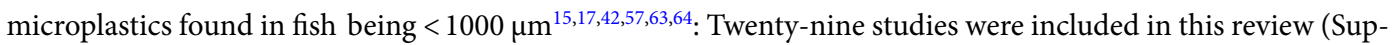
plementary Table S1). Some studies investigated numerous species, but only records of fishmeal-relevant species were processed for the microplastic concentrations assessment (Supplementary Tables S2, S3).

Manipulations of results from review studies were performed as follows: Mean values were reported unless otherwise stated. When concern about potential contamination with fibres existed based on the reported methods in the respective studies (if airborne controls were not performed or when performed but no further contamination mitigation was reported), microplastic concentrations were adjusted by subtracting fibrous microplastics from results when enough detail was provided by those studies. Mean overall microplastic abundances were calculated by obtaining total microplastic concentrations (mean reported or adjusted concentration $\times$ number of specimens of each study) and dividing those results by the total number of specimens of all studies. Standard deviations were calculated based on the mean abundance per species of each study. Theoretical concentrations of microplastics that could be anticipated in fishmeal samples were calculated based on information available of fishmeal-relevant species that are destined whole for production, detail of these calculations can be found in Supplementary Section "Quantification of theoretical microplastic concentrations in fishmeal".

Method development and assessment for extraction of microplastics from fishmeal. Materials. Method development was performed with two types of fishmeal (whitefish and sardine/anchovies). Whitefish fishmeal was obtained from two suppliers for quantification of microplastic concentrations. Samples of $40 \mathrm{~g}$ were used.

Method development background. Numerous studies digested fish tissue with $10 \% \mathrm{KOH}^{15,16,21}$. Visual or molecular damage to microplastics (hindering spectroscopy to establish polymer compositions) has been found to be minimal from exposure to $\mathrm{KOH}^{21,23}$. $\mathrm{KOH}$ is often recommended as the most suitable digestion method of biotic materials ${ }^{16,21,23,65-67}$. However, preliminarily trials revealed that $10 \% \mathrm{KOH}\left(1.82 \mathrm{M} ; 3 \times \mathrm{v} / \mathrm{v}\right.$, digested at $60{ }^{\circ} \mathrm{C}$ for $48 \mathrm{~h}$ ) was not able to digest fishmeal enough to be vacuum-filtered over $25-\mu \mathrm{m}$ filters. This filter size was chosen to allow catching at least a proportion of small particles $(<150 \mu \mathrm{m})$ that could potentially harm consumers due to their size ${ }^{45}$. Compared to the content of fish guts, fishmeal may contain higher concentrations of lipids and have more very fine fragments of bone from the grinding/milling process making the samples difficult to filter. The application of an acid reagent may digest those bony fragments; however, as previous comparisons between extraction reagents have shown, microplastic particles are likely to be compromised by this approach ${ }^{68}$. Since fishmeal is a matrix of small solid particles, density separation techniques were explored. Microplastics are often retrieved from sediment samples by means of flotation using brine solutions ${ }^{18,69,70}$. Saline solutions are more dense than water and therefore allow for a greater fraction of particles (i.e. with a lower density than the solution) to float to the surface and be removed, leaving heavier particles such as bones, shells and sediment behind ${ }^{18}$. Flotation with $\mathrm{NaCl}$ was successfully trialled as follows.

Sodium chloride density separations. Technique 1 Samples of $40 \mathrm{~g}$ fishmeal were weighed out into 400-ml glass jars. Approximately $3 \times$ the volume of the sample of saturated $\mathrm{NaCl}$ solution was added, almost filling the jar. Care was taken to not fill the jar to the top but keep a gap of approximately $10 \mathrm{~mm}$ between the liquid and the lid. This was done to ensure the same amount of liquid to be collected during each overflow. Lidded sample jars were shaken vigorously for $15 \mathrm{~s}$ and subsequently left to stand for a minimum of $30 \mathrm{~min}$. Jars were placed into a large beaker and saturated $\mathrm{NaCl}$ solution $\left(1.20 \mathrm{~g} \mathrm{~cm}^{3}\right.$, filtered through $1.2 \mu \mathrm{m} \mathrm{GF} / \mathrm{C}$ filters) carefully poured into the jar until the solution overflowed (see Supplementary Fig. S1 for setup). The outside of the jars were rinsed with copious amounts of ultrapure water. Supernatants were vacuum-filtered, and filters dried overnight at $40^{\circ} \mathrm{C}$ in closed petri dishes. Each sample was subjected to three extractions. Technique 2 Further, the Sediment-Microplastic Isolation unit developed by Coppock et al. ${ }^{71}$ was assessed. Their method was adapted as follows: $40 \mathrm{~g}$ fishmeal were weight out into the unit and approximately $540 \mathrm{ml}$ of saturated $\mathrm{NaCl}$ solution was added. The sample was stirred with a glass rod. The unit was placed on a magnetic stirrer for $5 \mathrm{~min}$ and left to stand for a further $5 \mathrm{~min}$. The sample was stirred again with a glass rod and the procedure repeated. This was to ensure wetting and total mixing of the fishmeal with the solution. The glass rod was rinsed each time with approximately $40 \mathrm{ml}$ of $\mathrm{NaCl}$ solution which was added to the sample. The unit was then left to stand for a further 40 min before the tap was closed. Different standing time compared to technique 1 was needed because fishmeal settled at a slower rate in the isolation unit, potentially because the fishmeal was stirred rather than shaken in the $\mathrm{NaCl}$ solution. The supernatant was poured into a glass jar, and the top part of the unit was rinsed with $200 \mathrm{ml}$ of $\mathrm{NaCl}$ solution, which was also transferred to the jar. The extraction procedure was performed three times per sample.

Recovery rates. Microplastics were created from five post-consumer items (mean size $298 \pm 201 \mu \mathrm{m}$ ). Fragments of polystyrene (PS; lid of disposable coffee cup, white), polypropylene (PP; single-use ready meal container, transparent) and polyethylene terephthalate (PET; bottle of cooking oil, green) were produced with an electrical coffee bean grinder. Particles were dry-sieved through stacked 63 and $600-\mu \mathrm{m}$ stainless steel sieves, retaining microplastics on the $63-\mu \mathrm{m}$ sieve. Fibres of nylon (PA; tutu fabric, yellow) and rayon (garment fabric, black) were cut from sheets of fabric. A subsample $50 \%$ of the created particles was measured using a Nikon SMZ1000 microscope equipped with a graticule. Ten particles of each material were added to triplicates of two types of fishmeal (sardine/anchovies and whitefish). The above-mentioned density separation techniques were used. For technique 1, four procedural blanks were run alongside the extraction process and vacuum-filtration was performed using cellulose filter papers, grade $4(25 \mu \mathrm{m})$. For technique 2, two procedural blanks were run alongside, and supernatants were filtered over $55-\mu \mathrm{m}$ aperture metal mesh. Recovered microplastics were manu- 
ally counted using a Nikon SMZ1000 microscope. Number of recovered microplastics was expressed as a percentage of dosed particles.

Microplastics in commercial fishmeal samples. Extraction and enumeration. Due to filtration issues when not taking absolute care during the overflow step, supernatants were filtered through $55-\mu \mathrm{m}$ aperture metal mesh disks (diameter $47 \mathrm{~mm}$ ). Whitefish fishmeal from two suppliers in triplicates were subjected to the above-mentioned extraction method. Without removing the lids, potential microplastics (in line with HidalgoRuz et al. ${ }^{18}$ and MERI ${ }^{72}$ ) were manually counted on the filters using a Nikon SMZ1000 microscope (magnification $\times 10-\times 80$ ) with attached CMEX500 digital camera. Particles were photographed and dimensions measured in Image ${ }^{73}$. Particles were then transferred onto $1.2-\mu \mathrm{m}$ GF/C filters for subsequent Raman analysis. Findings are expressed in means \pm standard deviation unless otherwise stated. Background information about calculating global annual microplastics input into the oceans through fishmeal can be found in Supplementary Section "Quantification of fishmeal as microplastics pathway to the sea". Kernel density estimation was performed with the Excel Add-In of the Royal Society of Chemistry ${ }^{74}$ and figures drawn in Microsoft Excel.

Particle composition verification. Potential microplastics were analysed using Raman spectroscopy (Renishaw inVia, excitation wavelength $785 \mathrm{~nm}$, reproducibility $<1 \mathrm{~cm}^{-1}$, absolute power $\geq 300 \mathrm{~mW}$, with Leica DM 25,000 M microscope, $\times 50$ magnification lens, WiRE 4.1 software). Particles were manually selected. Analysis was performed over the entire spectrum (Raman shift $0-3200 \mathrm{~cm}^{-1}$ ) with $1-100 \%$ laser power, $10 \mathrm{~s}$ exposure time and three accumulations. Particle spectra were compared against our own Raman polymer library, SLoPP $(e)^{24}$ and standard libraries in BioRad KnowItAll. Minimum acceptable scores were $70 \%$ for individual and multi-components results and $50 \%$ for peak results, all scores were also visually assessed. Particles were classed as 'inconclusive' when only dyes could be identified.

Contamination control. Researchers wore white $100 \%$ cotton clothing (headscarf, overall and laboratory coat). Clothing was lint-rolled prior to laboratory work each day to minimise the risk of sample contamination with fibres. Work surfaces were wiped down $3 \times$ with $70 \%$ ethanol. Work was performed in a clean air cabinet (Bassaire 03VB, BS EN ISO14644, class 5, with additional cover), except for microscopy work. Glass and metal ware were used whenever possible. GF/C filter paper and mesh were furnaced at $500{ }^{\circ} \mathrm{C}$ for two hours to remove potential plastic contaminants and stored in airtight containers until use. $\mathrm{NaCl}$ solutions were filtered over 1.2$\mu \mathrm{m} \mathrm{GF/C} \mathrm{filters} \mathrm{and} \mathrm{stored} \mathrm{in} \mathrm{glass} \mathrm{bottles} \mathrm{with} \mathrm{glass} \mathrm{lids} \mathrm{until} \mathrm{needed.} \mathrm{Dampened} \mathrm{filter} \mathrm{papers}(1.2-\mu \mathrm{m} \mathrm{GF} / \mathrm{C})$ were placed on work surfaces to assess potential airborne contamination in the clean air cabinet. Two procedural blanks were run alongside the samples and handled the same way as the samples. Blanks were sealed in Petri dishes, particles were counted and assessed with Raman spectroscopy the same way as fishmeal samples. Petri dishes were never opened during visual inspection for enumeration; lids were only removed after enumeration was complete for transfer of particles for spectroscopy.

\section{Data availability}

Data supporting this study are openly available from the University of Southampton repository at https://doi. org/10.5258/SOTON/D1400.

Received: 5 June 2020; Accepted: 30 December 2020

Published online: 21 January 2021

\section{References}

1. Golik, A. Debris in the Mediterranean sea: Types, quantities, and behavior. In Marine Debris (eds Coe, J. M. \& Rogers, D. B.) 7-14 (Springer, Berlin, 1997).

2. Gregory, M. R. \& Ryan, P. G. Pelagic plastics and other seaborne persistent synthetic debris: A review of southern Hemisphere perspectives. In Marine Debris (eds Coe, J. M. \& Rogers, D. B.) 49-66 (Springer, Berlin, 1997).

3. Matsumura, S. \& Nasu, K. Distribution of floating debris in the North Pacific Ocean: Sighting surveys 1986-1991. In Marine Debris (eds Coe, J. M. \& Rogers, D. B.) 15-24 (Springer, New York, 1997).

4. Galgani, F. et al. Litter on the sea floor along European coasts. Mar. Pollut. Bull. 40, 516-527 (2000).

5. Pham, C. K. et al. Marine litter distribution and density in European seas, from the shelves to deep basins. PLoS ONE 9, e95839 (2014).

6. Arthur, C., Baker, J. \& Bamford, H. Proceedings of the International Research Workshop on the occurrence, effects, and fate of microplastic marine debris. In NOAA Technical Memorandum NOS-ORぬR-30, 49 (2009).

7. Andrady, A. L. Microplastics in the marine environment. Mar. Pollut. Bull. 62, 1596-1605 (2011).

8. Cole, M., Lindeque, P., Halsband, C. \& Galloway, T. S. Microplastics as contaminants in the marine environment: A review. Mar. Pollut. Bull. 62, 2588-2597 (2011).

9. Muller-Karanassos, C. et al. Antifouling paint particles in intertidal estuarine sediments from southwest England and their ingestion by the harbour ragworm, Hediste diversicolor. Environ. Pollut. 249, 163-170 (2019).

10. Napper, I. E. \& Thompson, R. C. Release of synthetic microplastic plastic fibres from domestic washing machines: Effects of fabric type and washing conditions. Mar. Pollut. Bull. 112,39-45 (2016).

11. Murphy, F., Ewins, C., Carbonnier, F. \& Quinn, B. Wastewater treatment works (WwTW) as a source of microplastics in the aquatic environment. Environ. Sci. Technol. 50, 5800-5808 (2016).

12. Wright, S. L., Thompson, R. C. \& Galloway, T. S. The physical impacts of microplastics on marine organisms: A review. Environ. Pollut. 178, 483-492 (2013).

13. Farrell, P. \& Nelson, K. Trophic level transfer of microplastic: Mytilus edulis (L.) to Carcinus maenas (L.). Environ. Pollut. 177, 1-3 (2013).

14. Lusher, A. L., McHugh, M. \& Thompson, R. C. Occurrence of microplastics in the gastrointestinal tract of pelagic and demersal fish from the English channel. Mar. Pollut. Bull. 67, 94-99 (2013). 
15. Tanaka, K. \& Takada, H. Microplastic fragments and microbeads in digestive tracts of planktivorous fish from urban coastal waters. Sci. Rep. 6, 34351 (2016).

16. Foekema, E. M. et al. Plastic in North sea fish. Environ. Sci. Technol. 47, 8818-8824 (2013).

17. Digka, N., Tsangaris, C., Torre, M., Anastasopoulou, A. \& Zeri, C. Microplastics in mussels and fish from the Northern Ionian sea. Mar. Pollut. Bull. 135, 30-40 (2018).

18. Hidalgo-Ruz, V., Gutow, L., Thompson, R. C. \& Thiel, M. Microplastics in the marine environment: A review of the methods used for identification and quantification. Environ. Sci. Technol. 46, 3060-3075 (2012).

19. Galgani, F. et al. Guidance on monitoring of marine litter in European seas. JRC Sci. Policy Rep. https://doi.org/10.2788/99475 (2013).

20. Torre, M., Digka, N., Anastasopoulou, A., Tsangaris, C. \& Mytilineou, C. Anthropogenic microfibres pollution in marine biota. A new and simple methodology to minimize airborne contamination. Mar. Pollut. Bull. 113, 55-61 (2016).

21. Karami, A. et al. A high-performance protocol for extraction of microplastics in fish. Sci. Total Environ. 578, 485-494 (2017).

22. Renner, G. et al. Data preprocessing \& evaluation used in the microplastics identification process: A critical review \& practical guide. Trends Anal. Chem. 111, 229-238 (2019).

23. Thiele, C. J., Hudson, M. D. \& Russell, A. E. Evaluation of existing methods to extract microplastics from bivalve tissue: Adapted $\mathrm{KOH}$ digestion protocol improves filtration at single-digit pore size. Mar. Pollut. Bull. 142, 384-393 (2019).

24. Munno, K., De Frond, H., O’Donnell, B. \& Rochman, C. M. Increasing the accessibility for characterizing microplastics: Introducing new application-based and spectral libraries of plastic particles (SLoPP and SLoPP-E). Anal. Chem. 92, 2443-2451 (2020).

25. de Sa, L. C., Luis, L. G. \& Guilhermino, L. Effects of microplastics on juveniles of the common goby (Pomatoschistus microps): Confusion with prey, reduction of the predatory performance and efficiency, and possible influence of developmental conditions. Environ. Pollut. 196, 359-362 (2015).

26. Rochman, C. M., Kurobe, T., Flores, I. \& Teh, S. J. Early warning signs of endocrine disruption in adult fish from the ingestion of polyethylene with and without sorbed chemical pollutants from the marine environment. Sci. Total Environ. 493, 656-661 (2014).

27. Rochman, C. M., Hoh, E., Kurobe, T. \& Teh, S. J. Ingested plastic transfers hazardous chemicals to fish and induces hepatic stress. Sci. Rep. 3, 3263 (2013).

28. Tosetto, L., Williamson, J. E. \& Brown, C. Trophic transfer of microplastics does not affect fish personality. Anim. Behav. 123, 159-167 (2017).

29. Phuong, N. N. et al. Is there any consistency between the microplastics found in the field and those used in laboratory experiments?. Environ. Pollut. 211, 111-123 (2016).

30. Cunningham, E. M. \& Sigwart, J. D. Environmentally accurate microplastic levels and their absence from exposure studies. Integr. Comp. Biol. 59, 1485-1496 (2019).

31. FAO. The production of fish meal and oil. In FAO Fisheries Technical Paper 142, 1-63 (1986).

32. Shepherd, C. J. \& Jackson, A. J. Global fishmeal and fish-oil supply: Inputs, outputs and markets a. J. Fish Biol. 83, 1046-1066 (2013).

33. Cashion, T., Le Manach, F., Zeller, D. \& Pauly, D. Most fish destined for fishmeal production are food-grade fish. Fish Fish. 18, 837-844 (2017).

34. FAO. The State of World Fisheries and Aquaculture 2016. Contributing to Food Security and Nutrition for All (2016).

35. FAO. The State of World Fisheries and Aquaculture 2018-Meeting the Sustainable Development Goals (Food and Agriculture Organization of the United Nations, Rome, 2018).

36. Péron, G., François Mittaine, J. \& Le Gallic, B. Where do fishmeal and fish oil products come from? An analysis of the conversion ratios in the global fishmeal industry. Mar. Policy 34, 815-820 (2010).

37. Newton, R. W. Assessing environmental sustainability and value addition opportunities for by-products from aquaculture. $\mathrm{PhD}$ dissertation. (University of Stirling, 2014).

38. FAO. FAO Yearbook. Fishery and Aquaculture Statistics 2017 (Food and Agriculture Organization of the United Nations, Rome, 2019).

39. Hanachi, P., Karbalaei, S., Walker, T. R., Cole, M. \& Hosseini, S. V. Abundance and properties of microplastics found in commercial fish meal and cultured common carp (Cyprinus carpio). Environ. Sci. Pollut. Res. https://doi.org/10.1007/s11356-019-05637-6 (2019).

40. Karbalaei, S. et al. Analysis and inorganic composition of microplastics in commercial Malaysian fish meals. Mar. Pollut. Bull. 150, $110687(2020)$.

41. Woodall, L. C. et al. Using a forensic science approach to minimize environmental contamination and to identify microfibres in marine sediments. Mar. Pollut. Bull. 95, 40-46 (2015).

42. Bour, A., Avio, C. G., Gorbi, S., Regoli, F. \& Hylland, K. Presence of microplastics in benthic and epibenthic organisms: Influence of habitat, feeding mode and trophic level. Environ. Pollut. 243, 1217-1225 (2018).

43. Dris, R. et al. Microplastic contamination in an urban area: A case study in Greater Paris. Environ. Chem. 12, 592 (2015).

44. Allen, S. et al. Atmospheric transport and deposition of microplastics in a remote mountain catchment. Nat. Geosci. 12, 339-344 (2019).

45. Wright, S. L. \& Kelly, F. J. Plastic and human health: A micro issue?. Environ. Sci. Technol. 51, 6634-6647 (2017).

46. Browne, M. A., Dissanayake, A., Galloway, T. S., Lowe, D. M. \& Thompson, R. C. Ingested microscopic plastic translocates to the circulatory system of the mussel, Mytilus edulis (L.). Environ. Sci. Technol. 42, 5026-5031 (2008).

47. Collard, F. et al. Microplastics in livers of European anchovies (Engraulis encrasicolus L.). Environ. Pollut. 229, 1000-1005 (2017).

48. Smith, B. C. Fundamentals of Fourier Transform Infrared Spectroscopy (CRC Press, Cambridge, 2011).

49. Bakeev, K. A. \& Chimenti, R. V. Material Identification via Handheld Spectroscopy. European Pharmaceutical Review (2013). (Accessed 3 June 2020); https://www.americanpharmaceuticalreview.com/1504-White-Papers-Application-Notes/147135-Prosand-Cons-of-Using-Correlation-Versus-Multivariate-Algorithms-for-Material-Identification-via-Handheld-Spectroscopy/.

50. Catarino, A. I., Macchia, V., Sanderson, W. G., Thompson, R. C. \& Henry, T. B. Low levels of microplastics (MP) in wild mussels indicate that MP ingestion by humans is minimal compared to exposure via household fibres fallout during a meal. Environ. Pollut. 237, 675-684 (2018).

51. Brăte, I. L. N., Eidsvoll, D. P., Steindal, C. C. \& Thomas, K. V. Plastic ingestion by Atlantic cod (Gadus morhua) from the Norwegian coast. Mar. Pollut. Bull. 112, 105-110 (2016).

52. Cannon, S. M. E., Lavers, J. L. \& Figueiredo, B. Plastic ingestion by fish in the southern Hemisphere: A baseline study and review of methods. Mar. Pollut. Bull. 107, 286-291 (2016).

53. Huerta Lwanga, E. et al. Field evidence for transfer of plastic debris along a terrestrial food chain. Sci. Rep. 7, 14071 (2017).

54. Warman, P. R. The effect of fertilizer, chicken manure and dairy manure on timothy yield, tissue composition and soil fertility. Agric. Wastes 18, 289-298 (1986).

55. Rist, S., Carney Almroth, B., Hartmann, N. B. \& Karlsson, T. M. A critical perspective on early communications concerning human health aspects of microplastics. Sci. Total Environ. 626, 720-726 (2018).

56. Park, T. J. et al. Occurrence of microplastics in the Han River and riverine fish in South Korea. Sci. Total Environ. 708, 134535 (2020).

57. Huang, J. S. et al. Microplastic accumulation in fish from Zhanjiang mangrove wetland, South China. Sci. Total Environ. 708, $134839(2020)$. 
58. Su, L. et al. The occurrence of microplastic in specific organs in commercially caught fishes from coast and estuary area of east China. J. Hazard. Mater. 365, 716-724 (2019).

59. Wu, F. et al. Accumulation of microplastics in typical commercial aquatic species: A case study at a productive aquaculture site in China. Sci. Total Environ. 708, 135432 (2020).

60. Akhbarizadeh, R., Moore, F. \& Keshavarzi, B. Investigating a probable relationship between microplastics and potentially toxic elements in fish muscles from northeast of Persian Gulf. Environ. Pollut. 232, 154-163 (2018).

61. Shim, W. J., Hong, S. H. \& Eo, S. E. Identification methods in microplastic analysis: A review. Anal. Methods 9, 1384-1391 (2017).

62. Karbalaei, S. et al. Abundance and characteristics of microplastics in commercial marine fish from Malaysia. Mar. Pollut. Bull. 148, 5-15 (2019).

63. Zhang, F. et al. Food-web transfer of microplastics between wild caught fish and crustaceans in East China Sea. Mar. Pollut. Bull. 146, 173-182 (2019).

64. Markic, A. et al. Double trouble in the South Pacific subtropical gyre: Increased plastic ingestion by fish in the oceanic accumulation zone. Mar. Pollut. Bull. 136, 547-564 (2018).

65. Kühn, S. et al. The use of potassium hydroxide $(\mathrm{KOH})$ solution as a suitable approach to isolate plastics ingested by marine organisms. Mar. Pollut. Bull. 115, 86-90 (2017).

66. Dehaut, A. et al. Microplastics in seafood: Benchmark protocol for their extraction and characterization. Environ. Pollut. 215, 223-233 (2016).

67. Enders, K., Lenz, R., Beer, S. \& Stedmon, C. A. Extraction of microplastic from biota: Recommended acidic digestion destroys common plastic polymers. ICES J. Mar. Sci. 74, 326-331 (2017).

68. Catarino, A. I., Thompson, R., Sanderson, W. \& Henry, T. B. Development and optimization of a standard method for extraction of microplastics in mussels by enzyme digestion of soft tissues. Environ. Toxicol. Chem. 36, 947-951 (2017).

69. Thompson, R. C. et al. Lost at sea: Where is all the plastic?. Science (Washington) 304, 838-838 (2004).

70. Horton, A. A., Svendsen, C., Williams, R. J., Spurgeon, D. J. \& Lahive, E. Large microplastic particles in sediments of tributaries of the River Thames, UK-Abundance, sources and methods for effective quantification. Mar. Pollut. Bull. 114, 218-226 (2017).

71. Coppock, R. L., Cole, M., Lindeque, P. K., Queirós, A. M. \& Galloway, T. S. A small-scale, portable method for extracting microplastics from marine sediments. Environ. Pollut. 230, 829-837 (2017).

72. MERI. Guide to microplastic identification, 15 (2017).

73. Schneider, C. A., Rasband, W. S. \& Eliceiri, K. W. NIH image to ImageJ: 25 years of image analysis. Nat. Methods 9, 671-675 (2012).

74. Thompson, M. Representing data distributions with kernel density estimates. In AMC Technical Brief AMCTB No 4 (2006).

\section{Acknowledgements}

We would like to thank our laboratory technicians-especially Pilar Pascual-Hidalgo of the Faraday laboratory-for the support in executing this study. We are grateful to Professor David Coggon for providing feedback during the early stages of this manuscript. This work was supported by the EPSRC Doctoral Programme, a Southampton Marine and Maritime Institute Leverhulme Trust Doctoral Scholarship, the University of Southampton Work Experience Scheme, and the Blue Marine Foundation, London, UK. The funding bodies did not have any involvement in this study.

\section{Author contributions}

C.T. conceived the study, performed the method development and Raman work, analysed the data and drafted the work, M.D.H. supervised and revised various versions of the manuscript, M.S. assisted with the method development and performed extractions and microscopy work, G.S.H. performed Raman work, A.E.R. supervised the Raman work. All authors have discussed the results and commented and amended the manuscript.

\section{Competing interests}

The authors declare no competing interests.

\section{Additional information}

Supplementary Information The online version contains supplementary material available at https://doi. org/10.1038/s41598-021-81499-8.

Correspondence and requests for materials should be addressed to C.J.T.

Reprints and permissions information is available at www.nature.com/reprints.

Publisher's note Springer Nature remains neutral with regard to jurisdictional claims in published maps and institutional affiliations.

(c) (i) Open Access This article is licensed under a Creative Commons Attribution 4.0 International License, which permits use, sharing, adaptation, distribution and reproduction in any medium or format, as long as you give appropriate credit to the original author(s) and the source, provide a link to the Creative Commons licence, and indicate if changes were made. The images or other third party material in this article are included in the article's Creative Commons licence, unless indicated otherwise in a credit line to the material. If material is not included in the article's Creative Commons licence and your intended use is not permitted by statutory regulation or exceeds the permitted use, you will need to obtain permission directly from the copyright holder. To view a copy of this licence, visit http://creativecommons.org/licenses/by/4.0/.

(C) The Author(s) 2021 